\title{
AC 2011-1824: A CASE STUDY OF HOW PROJECT-BASED LEARNING HELPS INCREASE INTEREST, UNDERSTANDING, AND RELEVANCE IN ENGINEERING FOR LEARNERS
}

\section{Taylor Halverson, Brigham Young University}

Taylor Halverson earned a double major $\mathrm{PhD}$ at Indiana University in instructional technology and design and Judaism and Christianity in antiquity. He earned Master's degrees from Indiana University and Yale University. His Bachelor's degree was earned at BYU. Dr. Halverson spent several years working for Cisco in Silicon Valley where he designed creative learning experiences for thousands of customer service agents spread across the globe. Dr. Halverson currently works as a Teaching and Learning Consultant at BYU, assisting faculty members to enhance the student learning experience. He also is a part-time faculty member at BYU, teaching a variety of courses including "The History of Creativity in the Arts, Sciences, and Technology", and a part-time faculty member at Capella University, teaching online $\mathrm{PhD}$ learners in instructional technology and design. Dr. Halverson regularly presents at academic conferences and recently published a book on instructional design theory and practice.

\section{Rollin H. Hotchkiss, Brigham Young University}

Rollin H. Hotchkiss is a professor of Civil and Environmental Engineering at Brigham Young University (BYU) and holds the Ira A Fulton College of Engineering and Technology Leadership chair within the College. Dr. Hotchkiss has maintained a research interest in learning effectiveness in engineering during his years at BYU and at his previous posts at the University of Nebraska-Lincoln and Washington State University. He and his student co-author won the ASEE Best Zone Paper in 2008 for their work on computer-based instruction for engineering education in the developing world. Dr. Hotchkiss also conducts research in stream restoration with an emphasis on upstream fish passage through culverts. $\mathrm{He}$ serves as the president of the Environmental and Water Resources Institute, part of the American Society of Civil Engineers. He is a registered professional engineer and holds a specialty licensing certificate from the American Academy of Water Resources Engineers. 
A Case Study of How Project-Based Learning Helps Increase Interest, Understanding, and Relevance in Engineering for

Learners 


\section{Abstract}

Fluid dynamics can be a particularly challenging and intimidating subject for many students in engineering disciplines. However, by helping learners actively discover the relevance and application of the course principles to their own lives, their engagement in the content and enthusiasm for learning can increase. At Brigham Young University (BYU), we designed a competitive project-based learning curriculum for the 79 students in the Civil Engineering course "Hydraulics and Fluid Flow Theory" for the winter and fall semesters 2010. During each semester, students competed in small groups to develop an engaging storyboard that would teach an especially challenging engineering topic to those outside their discipline. The top three winning projects each won prize money. Additionally, the top project from each semester won the opportunity to be professionally developed by BYU's Center for Teaching and Learning. Though students felt some apprehension early on in each semester about this project-based approach to learning, by the end of each semester many of the students confirmed that this learning approach helped them to develop important skills (such as being better communicators and teachers of engineering principles), perform better in teams, develop deeper interest in civil engineering, and to see the application of civil engineering principles to many areas of their everyday lives.

This is a case study report documenting student-reported impacts that the project-based learning approach had on student learning and suggested pedagogical improvements for using projectbased learning in this specific course. Based on the collected data, students felt that the competitive project-based approach to learning was helpful to them. They were required to think in new and innovative ways and learn to enhance their communication and teamwork skills, though they thought the timing and the sequence of some aspects of the project-based portion of the course could be revised to better fit the course flow and structure. Students explained that when they were asked to find creative ways to teach the engineering principles to others they found greater relevance in the course material to their own lives and greater engagement to master the material.

\section{Introduction}

In recent years, engineering education has identified and sought to address a variety of engineering abilities required for success in industry. Some of those skill areas include communication, teamwork, design experiences, and integrating theory and practice (i.e., applying learning in everyday life; seeing and making the connections between what is learned and everyday life). ${ }^{1}$ In response to these identified needs, accrediting agencies and other institutions (e.g., ABET, ASCE) have recommended changes to engineering educational practices to more fully meet these needs. ${ }^{2,3}$ Team-based and project-based learning is one valid educational practice that can help learners meet these objectives. ${ }^{4}$

In a fluid dynamics course taught at Brigham Young University (BYU), we introduced a teambased and project-based assignment, believing that students would recognize that such an assignment could help them develop better communication, teamwork, design, and application competencies. We also reasoned that students would report deeper understanding of and interest in engineering concepts. 
We followed up with learners through surveys to solicit their perceptions regarding how well the project-based assignment helped them better understand fluid dynamics concepts, see applications of the concepts in other areas of their lives, and to increase their interest in the topic. We also wanted student feedback on how to improve upon the learning experience for future students.

We were not attempting to provide a quantitative answer for why one type of learning approach is better than another (e.g., project-based vs. traditional teaching methods). This type of research question is often best answered in educational research using quasi-experimental methods. We were not attempting comparative research; we were more interested in the students' perceptions of their learning experience. Thus we did not create a control group or compare grades or other learning outcomes across groups of learners. Rather we wanted to gather rich, qualitative data to learn from students if they believed that the team-based and project-based learning helped them to achieve certain learning outcomes. Hence, our research questions sought to understand student perspectives and reactions to their learning experiences. Did students think that a teambased, project-based assignment helped them to develop engineering competencies? Did students think that they are better able to integrate theory and practice and thus see applications of engineering principles in the world around them?

Secondarily, we wanted to improve upon the instructional design of the assignment and learning experience for the students using a type of formative research. Formative research seeks to improve upon existing practices by gathering feedback and making targeted changes. We wanted to hear from the learners what worked for them and what didn't with the project-based assignment that we implemented. The suggestions for improvement received from the students may help us to improve upon the learning experience future students have with the project-based assignment. $^{5}$

The purpose of this paper is to share the case study data we gathered from the students who participated in the winter and fall 2010 semesters "Hydraulics and Fluid Flow Theory" course. This paper will present student-perception data that project-based, team-oriented instructional activities can help increase learners' understanding of and interest in the topic and ability to see applications of the topic in the world around them.

Why case study research?

Case study is an appropriate research method when rich details are sought for a particular circumstance that may be especially informative or interesting. Though case study research is slighted for perceptions of lack of generalizability to other situations and for the perception of lack of rigor in the research, case study research can be very valuable for providing rich details concerning a particularly interesting or noteworthy situation. ${ }^{6}$

Why project-based learning (PBL)?

We chose a project-based learning (PBL) approach for the assignment because it is a method well suited to help engineering students develop the general skills required for industry that both 
the ABET accreditation standards (especially outcomes 3a, 3d, 3g and 3i) ${ }^{2}$ and ASCE BOK2 (especially outcomes $8,16,21$, and 23$)^{3}$ have identified as important. We also reasoned that for the specific purposes we were hoping to accomplish with our course modifications that PBL would help us to achieve those things. ${ }^{7}$

Though project-based learning can mean different things to different people, ${ }^{8}$ our use of the term encompasses the idea that a specified problem or task is answered, solved, or completed in stages across time. Project-based learning is known for helping learners to be more actively involved in constructing their own learning and thereby creating deeper learning, requiring students to develop their learning in social interactions with others, and thus negotiate meaning and learning in the process. ${ }^{4}$ Project-based learning can provide an opportunity for students to perform across the six levels of Bloom's modified taxonomy of learning: Remember, understand, apply, analyze, evaluate, and create. ${ }^{9}$ Furthermore, project-based learning encompasses problem-based learning, another popular pedagogical approach used in engineering education to engage learners in meaningful challenges so that they can develop the relevant competencies necessary for success in industry. ${ }^{10}$

What we designed

We designed a team-oriented, project-based, competitive assignment for students to work on throughout the semester. We implemented this learning activity in the Civil Engineering course "Hydraulics and Fluid Flow Theory", a junior-level 3-credit, semester-long course required for all Civil Engineering majors at BYU. The major topics covered in the class are fluid statics and fluid dynamics. This course follows a traditional 3 credit engineering education lecture format supplemented by an every-other-week fluid mechanics lab experience. In this course, the lab portion constituted 15\% of the overall course grade; about $2 \%$ earned for each lab experience. The project-based assignment was worth 3 labs - the brainstorming activity was worth $1 / 2$ lab, the project idea write up was worth 1 lab, and the final storyboard presentation was worth 1.5 labsfor a total of $6.5 \%$ of the overall course grade.

What was the final student-team product we asked them to create? Student teams were asked to produce a storyboard poster presentation that conveyed an engaging way to teach a specific concept of their choice from the fluid dynamics class. A storyboard is a graphical representation of concepts, narratives, or products and is usually presented in sequential, linear, story-telling format. Comic strips are probably the most pedestrian, but widely recognized, example of storyboards. Storyboards are used in a variety of settings as a way to outline or blueprint a concept, story or a product before final production. We asked teams to create storyboards because narrative and story-telling can be effective, engaging methods for teaching concepts. Additionally, because of time and resource constraints we wanted students to focus on how to teach an engineering concept to someone else instead of spending their time creating the final instructional resource. Therefore, the storyboard functioned as the outline or blueprint for how the completed instructional product should look and perform.

The teams were given a day and a time near the end of the semester when they would pitch their instructional concept to a panel of judges that included the professor teaching the class and several instructional design and media development experts from BYU's Center for Teaching 
and Learning (CTL). The proposed instructional projects were presented in storyboard mode on 2' x 3' poster. Each poster was put on public display on the same day in the common study lounge of the College of Engineering. This was done so that students could make the results of their work visible to others outside of class, feel a sense of accomplishment and ownership for work well done, and for the judges to efficiently view all the proposals. Over the course of two hours, the judges met with each team in front of their poster and listened to the sales pitch, while taking notes on a score sheet. After reviewing all of the proposed instructional projects, the judges gathered privately to compare notes and scores. The top three winning project proposals were identified and announced the following day in class. The top three teams won prize money of $\$ 150$ for $1^{\text {st }}$ place, $\$ 75$ for $2^{\text {nd }}$ place, and $\$ 60$ for third place (thanks to the generosity of BYU's College of Engineering to sponsor these cash awards). Additionally, the winning project landed the commitment from BYU's CTL to professionally produce, free of charge, the proposal as an instructional video project.

With the students' end product in mind we'll roll the clock back to describe what we did to help students be successful in team-based, project-based learning. In preparation for the winter 2010 semester, we asked students in the fall 2009 class to scour the internet for creative and effective instructional examples of fluid mechanics processes. We were attempting to create a library of instructional examples that future students could review as they prepared to propose ways to teach fluid dynamics concepts to those outside the field. This is what was asked of all 2009 students:

- Search the internet for novel, imaginative, creative, and EFFECTIVE examples of fluid mechanics processes. Turn in this paper on Monday, November 30, and fill in the blanks below.

- $\quad$ Record the web site address (please write legibly; we will go to the site).

- What topic from the syllabus does this example cover? List the topic, date, and reading corresponding to the topic from the syllabus.

- Why do you think the presentation is effective?

- How would you improve this presentation?

- What did your family think of the presentation?

We included the last question specifically because we wanted the engineering students to learn to teach these topics to those outside the discipline. If one can effectively teach a concept to someone outside the discipline, they are far more likely to be able to teach it effectively to someone within the discipline who is already motivated and interested to know about the topic. The collected suggestions of effective teaching examples of fluid dynamics gathered by the fall 2009 students were shared with students in winter and fall 2010 when the competitive project assignment was introduced.

Early in the winter 2010 semester we introduced the project assignment to the students, provided them examples of past project on related topics, and discussed the breakdown of activities leading up to the final storyboard proposal. We also invited them to form teams. Though engineering education literature discusses best practices in team formation ${ }^{11,12}$ such as trying to form teams based on personality types as revealed by Herrmann Brain Dominance Instrument (HBDI), ${ }^{13,14,15}$ we opted to allow students to self-select their own teams. We do recognize the 
value in carefully establishing teams following a variety of well-research suggestions. However, due to time constraints and class focus, we worried that too much time spent on the team formation process would distract from the main purpose of the course (mastering concepts of fluid dynamics). Since the team-based and project-based assignment of creating a storyboard proposal was only one portion of the class (constituting only 6.5\% of the overall course grade) it seemed to us more valuable to let students be motivated to work together with friends and people they knew (this was a small class of majors) than to distract students with a lot of team building activities. We recognize that there can be drawbacks to this shorthand approach. Though, based on the survey data from learners, few students reported adverse experiences from working together in teams.

To provide structure to the overall task and provide guidance on expectations, we gave students a series of benchmark dates and activities to complete during the 16 week semester. When we announced this team-based project assignment to the class, we shared a one page hand-out with the students that summarized the purpose, audience, deadlines, and expectations of the project (see Figure 1). The deliverable dates actually changed once we got into the semester, after we recognized that students needed a bit more time at the brainstorming and proposal explanation stages. Hence the March 5 date shifted to the following week. Similarly, we shifted the presentation deadline from March 22 to two weeks later on April 6. We believe that these schedule decisions provided helpful time for the students to more fully develop their ideas and storyboards. 


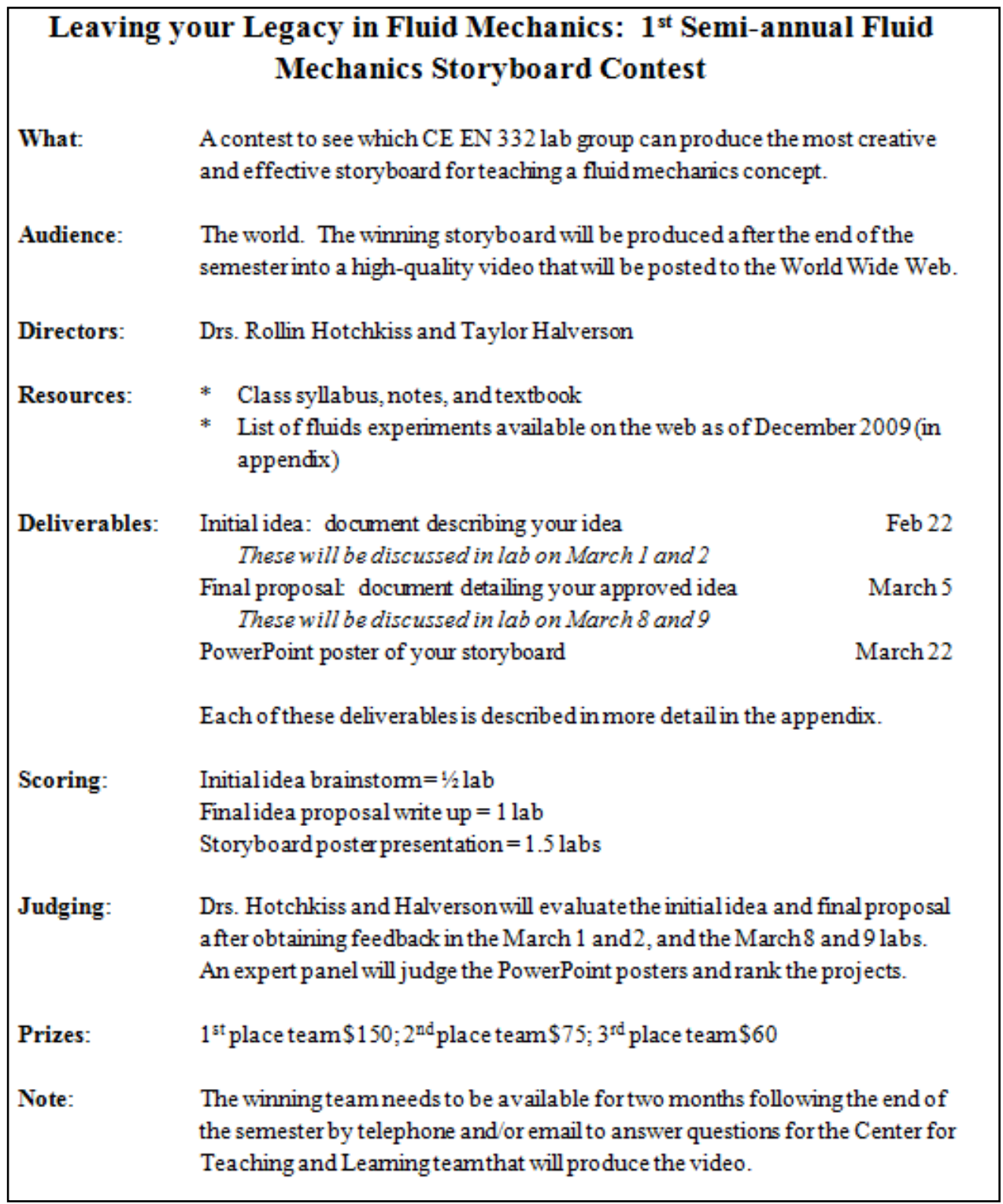

(Figure 1: Early semester project assignment information sheet)

By week 8, teams needed to review examples and check for other examples on the internet or elsewhere that creatively taught fluid mechanics principles. And they had to submit a sheet of brainstorming ideas for potential topics that they could develop into a storyboard proposal. The assignment included the prompts displayed in Figure 2.

Step 1: In the space below, brainstorm with your teammates some ideas for teaching. Take your ideas from the first 7 chapters of your text. In a brainstorming session, there are NO bad ideas. Just think out loud and write them down.

Step 2: Now, as a team, discuss the ideas from the previous sheet and choose your top 3-4 ideas. Rank them below, your favorite idea first, and fill in a bit more as indicated.

Idea 1: Process to be taught: 
From textbook chapter

Ideas for teaching:

Idea 2: Process to be taught:

From textbook chapter

Ideas for teaching:

Etc.

(Figure 2: Brainstorming assignment for fluid mechanics storyboard contest)

We reviewed the brainstorming ideas and provided feedback to the students, highlighting ideas that had merit, and recommending that students develop those into storyboard proposals or, where needed, inviting students to brainstorm again to produce more actionable ideas. Those who needed to produce additional ideas submitted fresh brainstorming sheets the following week and once again we provided feedback and suggestions on actionable ideas.

Originally, we had requested that student teams submit (week 9) their detailed proposal of what concept they would be teaching one week after they had submitted their brainstorming activities (week 8). However, because some teams needed to redo their brainstorming activity, and, because we thought it would be helpful for students to have one more week to formulate the main outline of their project, we gave students until week 11 of the semester to submit their final proposal. We reviewed the final proposals and offered feedback to guide the student teams as they worked to complete the storyboard poster presentation. This final assignment activity was also pushed back a few weeks from the original date (from week 12 to week 14) in order to give teams more time to consider instructor feedback and to well develop their instructional project idea. The storyboard display process was documented earlier in this paper.

\section{Project final production}

Working with the winning team and their project proposal, BYU's CTL made use of its resources and its professionally trained staff to develop the winning project proposal into a completed instructional product. This process required coordinated efforts from the animation team, video team, and instructional design experts at the CTL. The effort involved creating animated sequences, producing a film script, securing actors and film locations. The film was shot in high definition, edited, the animations added as introductory and concluding components, and then loaded to the CTL's YouTube channel at http://www.youtube.com/watch?v=z7W4oEJ6XeI.

Despite careful production, there were a few minor mistakes that crept into the final product. Most notably the CTL didn't do an aural review of the script. All of the confirmed scripts had been reviewed in text-based format only. Thus, when the CTL recorded voice over for the introductory and concluding sequences and when actors spoke, one of the key terms of the theory (Eulerian) was repeatedly mispronounced (“you-larian” instead of the correct “oh-larian”). It wasn't until after the filming had been shot and edited and the content expert was reviewing the product that this mispronunciation became evident. Nevertheless, this minor error does not change the overall efficacy of the video instruction. 
Fall 2010 course

The timing and structure of the project-based assignment in the fall 2010 course mostly followed what was described for the winter 2010 course, though there were some changes. Learning from the winter 2010 experience, we schedule the initial brainstorming activity for week 8, the final project idea proposal for week 11, and the final storyboard presentation for week 14. A panel of judges was not used to select the winning project (just the professor and one representative from the CTL). The winning project was awarded the opportunity to be professionally developed and received a cash prize.

Survey instruments and responses

Now that we have reviewed how we designed and implemented this team-oriented, project-based assignment, we'll discuss the instruments that we used to collect feedback from students who participated in the course. Our purpose in gathering this information was to accomplish the following things. First, we wanted to verify that the project-based learning, at least from a student perception perspective, met the purposes for why we implemented it in the first place. Can team-based, project-based learning assignments that require learners to plan and design how to teach others the course concepts increase subject matter mastery, interest in the subject, and the ability to see applications of the content in the everyday world? The survey data helped us to answer these questions. Momentarily, we'll share that data as evidence that according to the students the project assignment had the intended effect.

Second, from an instructional design standpoint for the course, we wanted to learn what worked for student learning and what didn't. These comments from the students should help us to make changes to the project assignment so that it is more beneficial for learners in future classes. Before we share the data, let us review the instruments we used to gather student input.

Survey 1 for winter 2010 students

We collected data in the following ways. We devised a short paper-based survey that was given to each of the winter 2010 students near the end of the winter semester (April 2010). This survey focused on the two main purposes discussed above. We asked winter 2010 students to provide feedback on their experience with the projects during the semester. Twenty-two responded from a total of 26 students, which constitutes an $85 \%$ response rate. The questions we asked students were:

1. What was the most important thing (skill, concept, knowledge) that you gained from this project?

2. What would you change about the project process or deliverables to make it a better learning experience for you?

3. Any other feedback?

Survey 2 for both winter and fall 2010 students 
We created another survey that we loaded into Qualtrics ${ }^{\mathrm{TM}}$ survey software and emailed to winter 2010 and fall 2010 class participants. This survey focused primarily on the second purpose described above. This data was collected in mid-January 2011 once formal IRB approval was granted. The survey questions were delivered via email to a total of 79 students. We had a $48 \%(n=38)$ response rate to this survey. Thirteen of the 26 winter students responded (50\% response rate) and 25 of 53 fall students responded (47\% response rate) (see Figure 3).

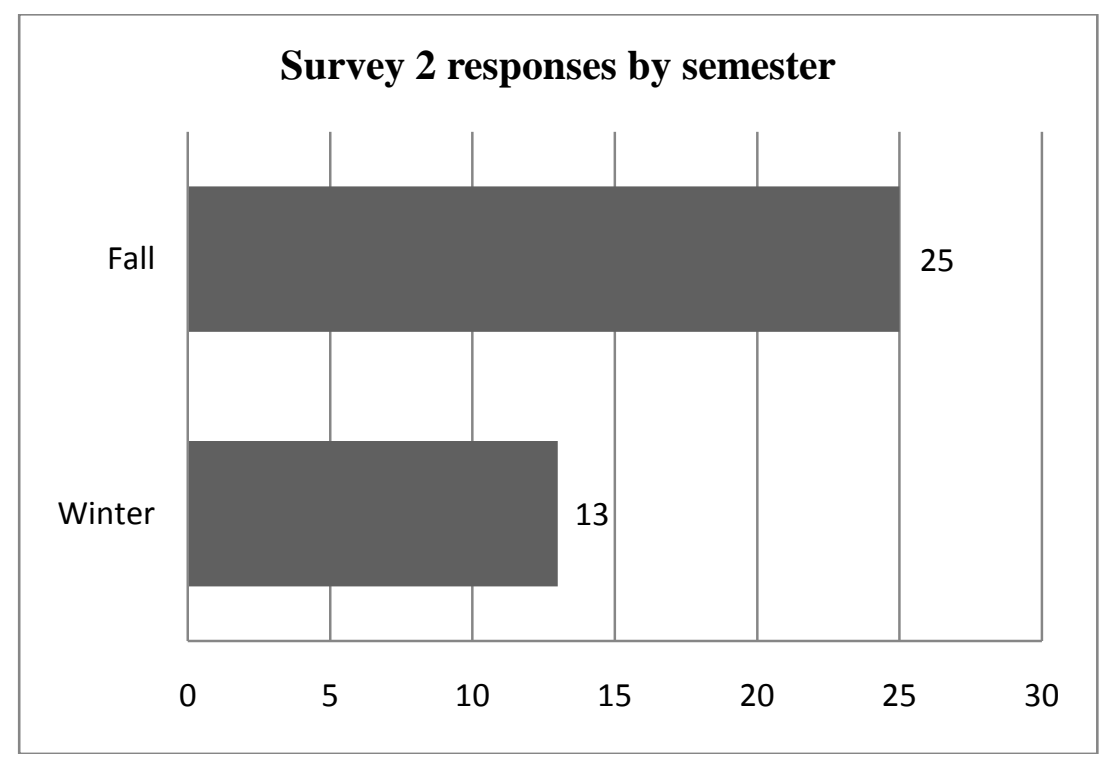

(Figure 3: Survey 2 responses by semester)

These are the questions we asked students on the second survey:

“Because of the team-based project experience I had in Dr. Hotchkiss' fluid dynamics course at BYU...

1. my understanding of fluid dynamics increased."

2. my interest in the topic of fluid dynamics increased."

3. I have seen applications of fluid dynamics in other areas of my life.”

4. Please provide specific examples and additional explanation for each of your answers.

5. Which semester did you take the course: winter 2010 or fall 2010 ?

Questions 1 - 3 were answered along a 5 point Likert-type scale. Question 4 was an open-ended response that allowed students to expand upon their answers in questions $1-3$. And question 5 simply allowed us to distinguish winter 2010 student responses from fall 2010 student responses.

Response Rates

Response rates are important element in determining the extent to which the survey data is nonbiased. Generally, higher response rates are desired. ${ }^{16}$ A recent meta-analysis of studies comparing the response rates of web surveys and paper-based surveys found a mean response rate of $34 \%$ for web surveys and $45 \%$ for paper-based surveys. ${ }^{17}$ 
Valuably for this study, the response rates to both the surveys we conducted are at the high end of mean responses to surveys (i.e., paper-based survey 1 response rate $=85 \%$; web and emailbased survey 2 response rate $=48 \%$ ). How did learners respond and what does it mean? We'll cover these questions in the next section.

Survey results

Survey 1 (for winter 2010 students)

Twenty-two winter semester 2010 students responded to the paper-based survey asking them what they had learned from the project, what suggested improvements they'd make, and other general feedback they'd like to share. Some students shared multiple comments and a few none at all. Reviewing and coding the comments revealed the following categories

In their responses to the survey question, "What was the most important thing (skill, concept, knowledge) that you gained from this project?” students highlighted:

- How to better teach engineering principles to others $(n=14)$.

- How to create a storyboard $(n=6)$.

- How to make the content more relevant to their lives by seeing applications of the principles in the world around them $(n=6)$.

- How to successfully work in a team $(n=4)$.

- Better understanding of course content $(n=2)$.

- $\quad$ How to be more creative $(n=1)$.

Representative student comments include:

- "It was fun to find ways to apply fluids principles to things that we see in the world."

- "I learned how to print a professional poster and I learned how to try and explain a complicated subject to a new audience.”

- "Trying to present somewhat difficult principles in a very elementary way was a challenge but it definitely was a benefit to help me communicate better and explain concepts.”

- "It was interesting to put a fluids concept into a story to be understood by those who have never heard it."

- "The most important skill is to be able to link a concept to something that is familiar to most people."

- "What I am learning in class does apply to the real world."

- "Working together on something that none of the people in our group were comfortable doing."

- "The ability to make a complex concept easy to understand.”

Responding to the survey question, "What would you change about the project process or deliverables to make it a better learning experience for you?” students suggested that the course should:

- Clarify project expectations $(n=14)$.

- Share more examples of successful projects $(n=6)$. 
- Change the timing of the project assignments $(\mathrm{n}=3)$.

- Change the scope of the project assignments $(n=2)$.

- Provide more feedback from the professor $(n=2)$.

- Change the way the project-based assignment is taught $(\mathrm{n}=2)$.

- Provide more opportunities for us to teach what we've learned to others $(\mathrm{n}=1)$.

Representative comments from students are:

- "It was difficult to think about the project during the beginning of the semester when we didn't have much knowledge of fluid dynamics. I would have started the assignment a little later with the same presentation date.”

- "Some more direction along the way, like if we're supposed to create a story or just a concept, etc."

- "Maybe better explain what some of the requirements to make it into a film production so that production is not limited by the complexity of the story."

The last question on this survey asked if students had any other feedback to share. Eight students provided comments. One student complained that one of the judges did not give their team a fair hearing on presentation day. Another student reiterated the need for clear project assignment expectations. Another asked for money to subsiding storyboard printing costs. However, the majority of general feedback comments indicated that students enjoyed the project $(n=5 ; 63 \%)$ :

- "This was a fun project. I really enjoyed doing it. My group rocks!"

- " "I had a lot more fun doing this than I thought I would."

- "I liked the entire project."

These formative suggestions for improvement will help us to make the project-based assignment better for future iterations of the course.

Survey 2 (for all winter and fall 2010 students)

We turn now to review the data generated from the second survey that was sent to all 79 students who had enrolled in the course either winter or fall 2010.

Survey 2 question: Did the project increase your understanding of the topic?

Overall responses to the question of whether the team-based projects contributed to better understanding of the material, on a 5.0 Likert-type scale, the mean response was 4.0 across both semesters (see Figure 4), indicating a high level of agreement that the project did contribute to an increased understanding of the topic. 


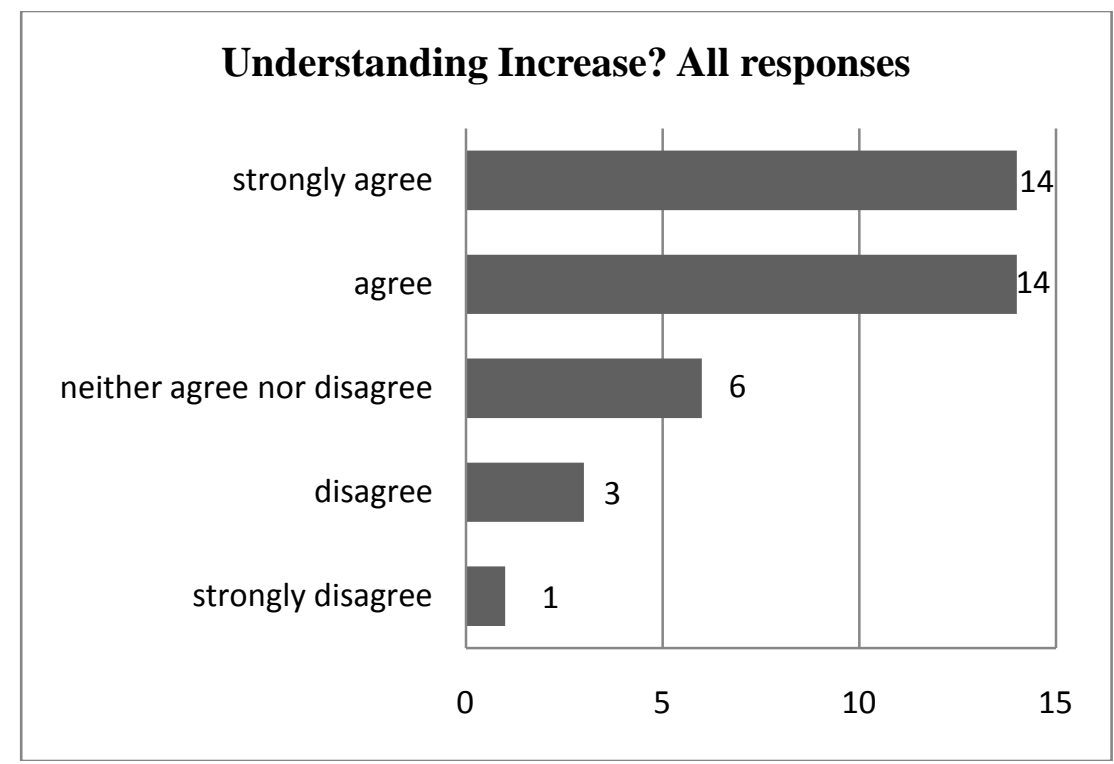

(Figure 4: Combined semester responses: "Did the team-based project increase your understanding of the topic?”)

Breaking the data down between semesters, the mean scores were nearly the same on this question (winter 2010 mean $=3.9$; fall 2010 mean $=4.0$ ), though for mixed reasons. In the winter semester, fewer students were ambivalent about how well the project helped increase their understanding of the material (see Figure 5). Whereas during the fall semester, there was a mix of ambivalent students offset by students who were clearly convinced that the project-based approach to learning helped them understand the material better (see Figure 6). Nevertheless, the positive data confirm that a majority of students believed that the projects increased their understanding of the material, confirming to us, at least from a student perspective, of the value of project-based learning to achieve the assignment learning objectives.

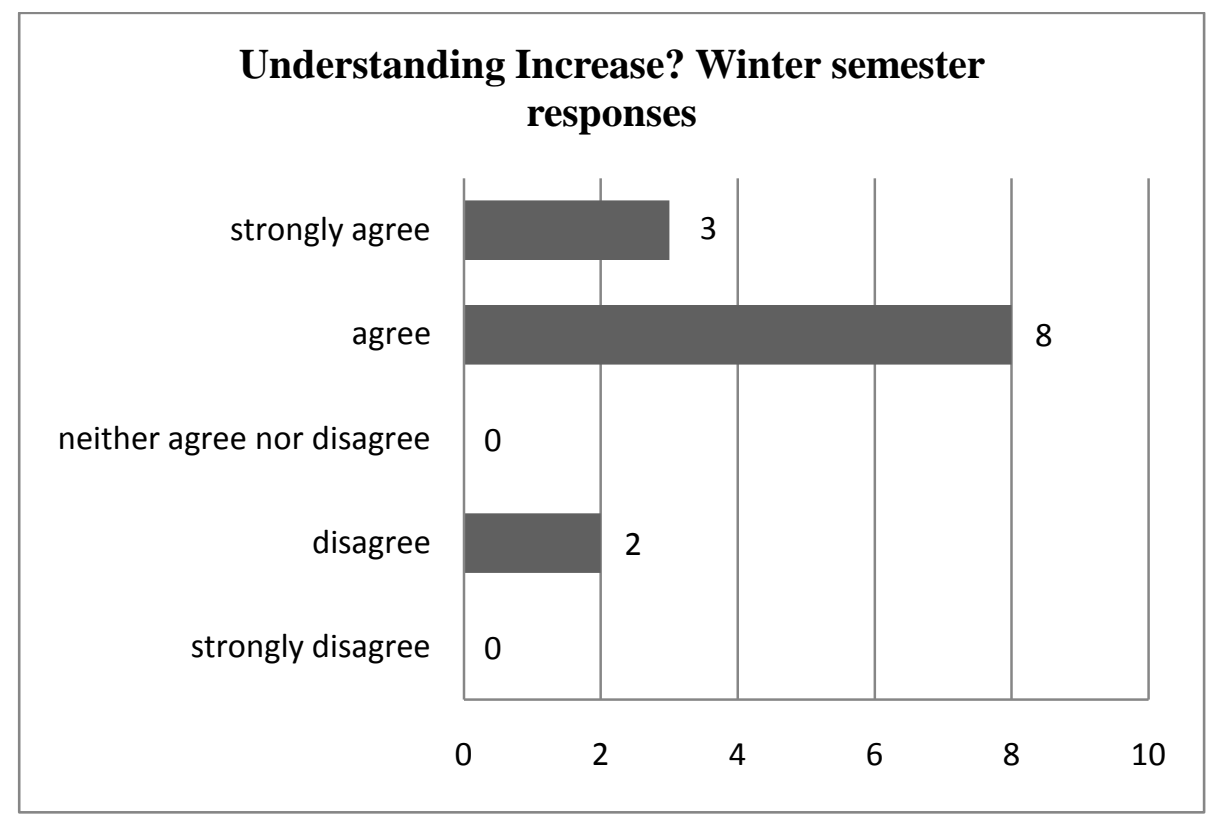


(Figure 5: Winter semester responses: "Did the team-based project increase your understanding of the topic?”)

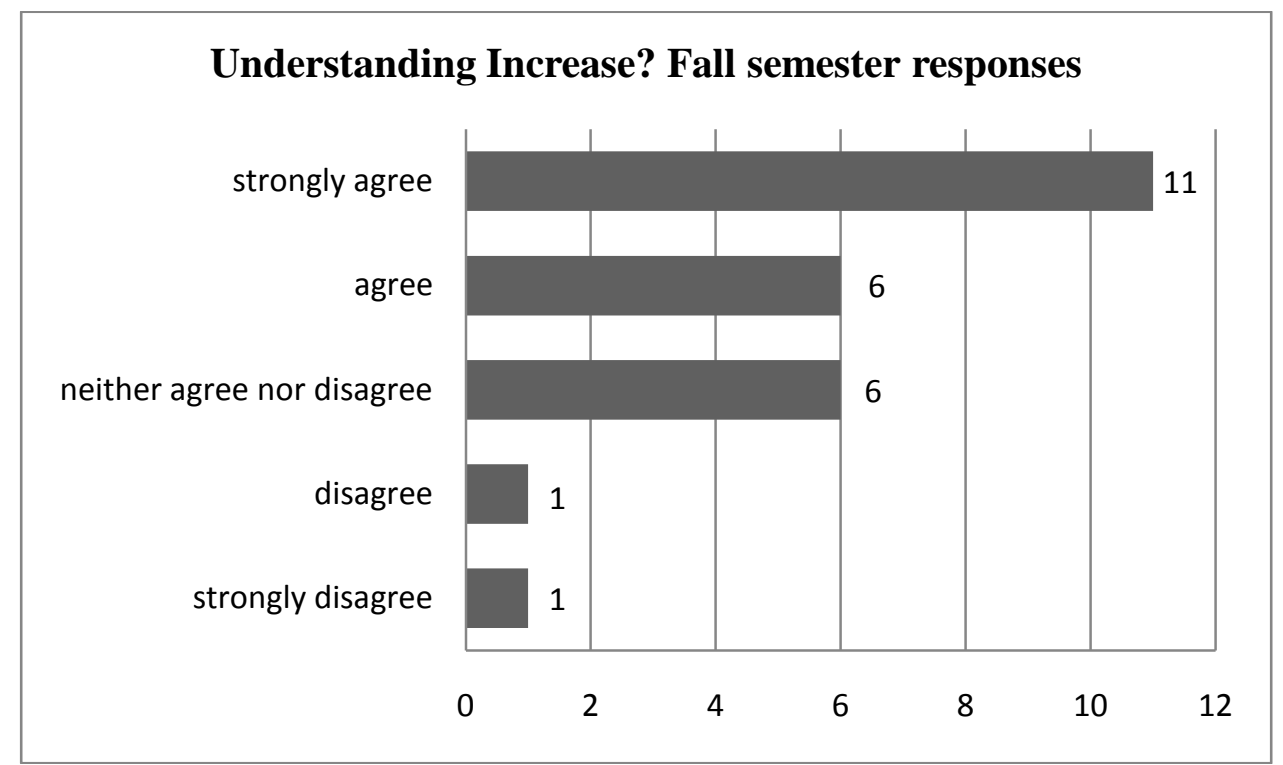

(Figure 6: Fall semester responses: "Did the team-based project increase your understanding of the topic?”)

What specifically did students from the winter and fall semesters say about how the project helped them to learn the material? Please note that student comments have been shared with minimal editing. Only an occasional spelling or minor grammar fix was included to ease readability.

Winter 2010 student comments on understanding the material:

- "I can think of things that I learned as a result of the project, and therefore my understanding increased. I found it helpful to continue spending time on difficult concepts even we had long surpassed them in the lectures and the homework. Especially since the time spent was geared toward teaching the subject and that requires a good understanding of a subject."

- "I had to study in order to create this storyboard. It made me want to understand the background of the topic."

- "My understanding of fluid dynamics increased as I worked with my group to find a way to explain a fluid dynamics topic to somebody without an engineering background."

Fall 2010 student comments on understanding the material:

- $\quad$ "The team project made me study the Reynolds Transport Theorem derivation much more thoroughly than I otherwise would have. Also, in attempting to come to a unified approach to explaining the theorem, a deeper understanding was gained because each person was able to confirm or add new insights to each other group member's understanding." 
- "The team project caused me to make sure I understood the background behind the Reynolds Transport Theorem in order to teach it to others in a succinct and clear manner. I was excited when I put in the time for my team and we were one of the leaders in understanding the first time around. It made me feel like my contributions were helpful and exceptional. The project also helped me relate hard concepts to daily experiences that others would understand."

Survey 2 question: Did the project increase your interest in the topic?

Student responses about the impact the project had on increasing their interest in the topic matter were lower overall than on the questions of increasing their understanding or their ability to see applications in the real world. Nevertheless, the overall mean score was 3.7 between both groups (see Figure 7), though the fall group scored a mean of 3.5 (see Figure 8) while the winter had a mean score of 4.0 (see Figure 9). There was a bit more ambivalence during the fall semester. As was seen in the "understanding" category, students positively agreed that the projects helped them develop interest in the subject matter.

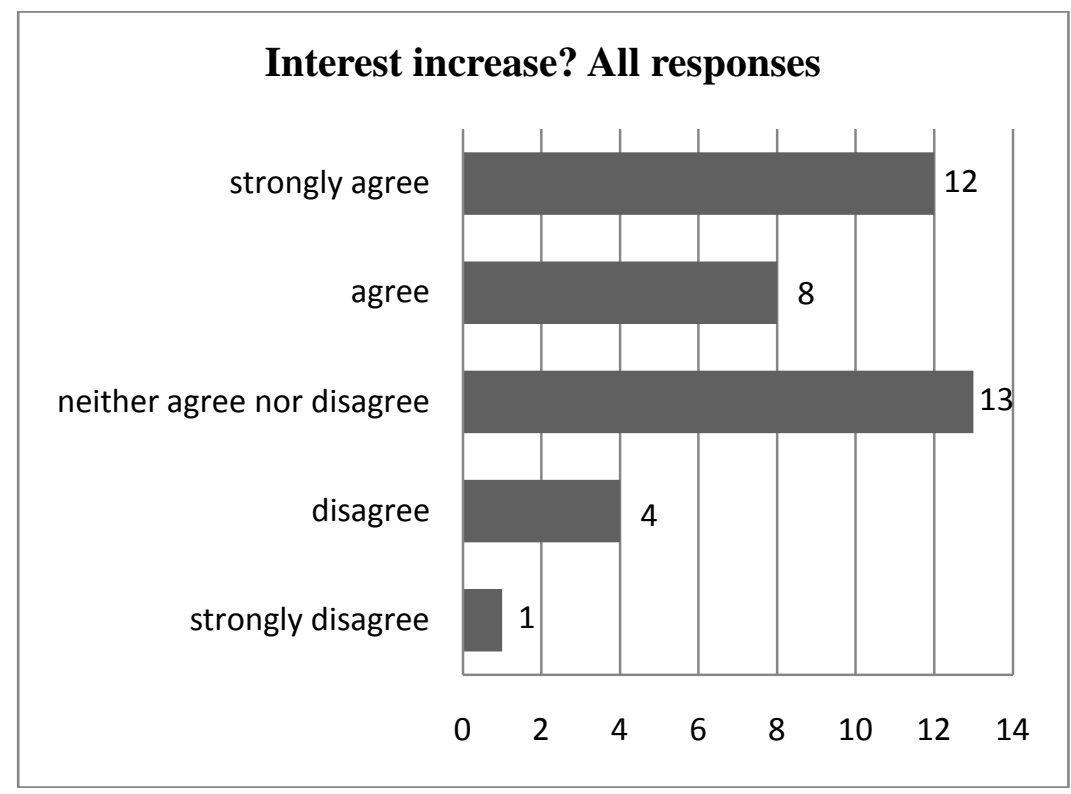

(Figure 7: Combined semester responses: "Did the team-based project increase your INTEREST in the topic?”) 


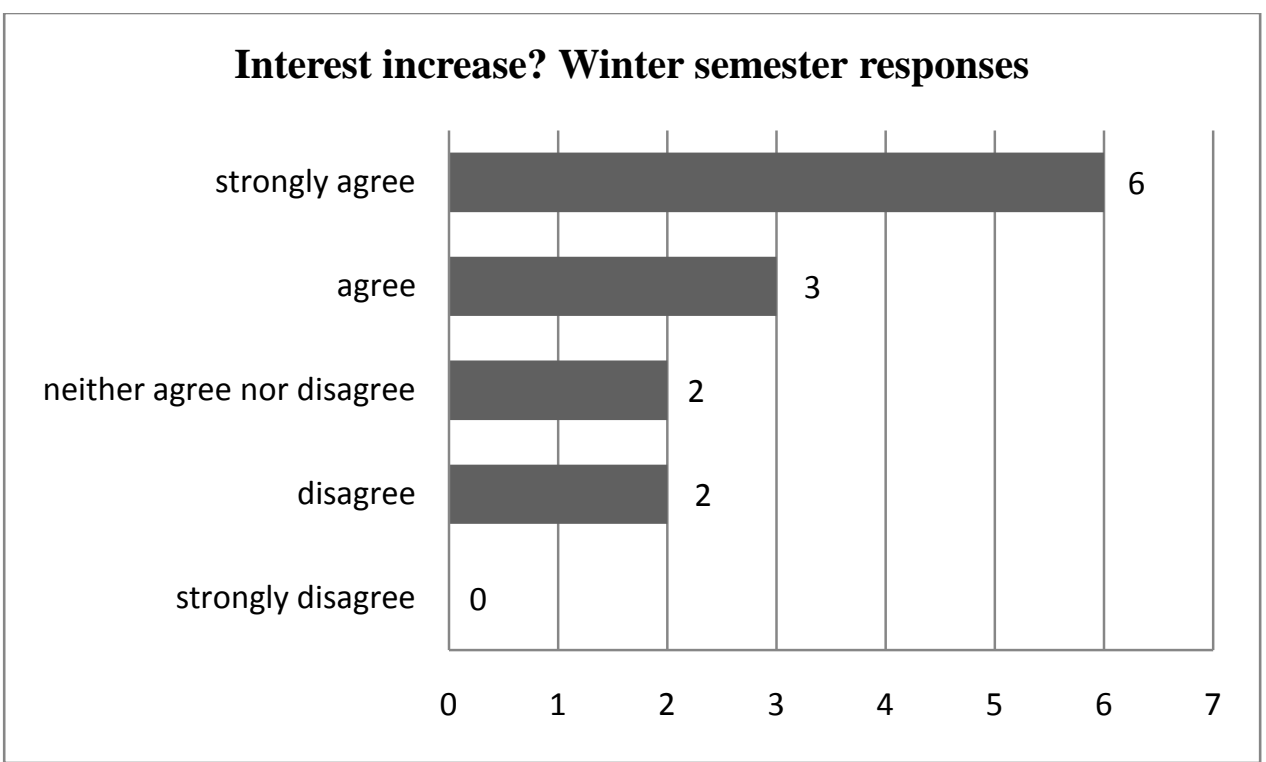

(Figure 8: Winter semester responses: "Did the team-based project increase your INTEREST in the topic?”)

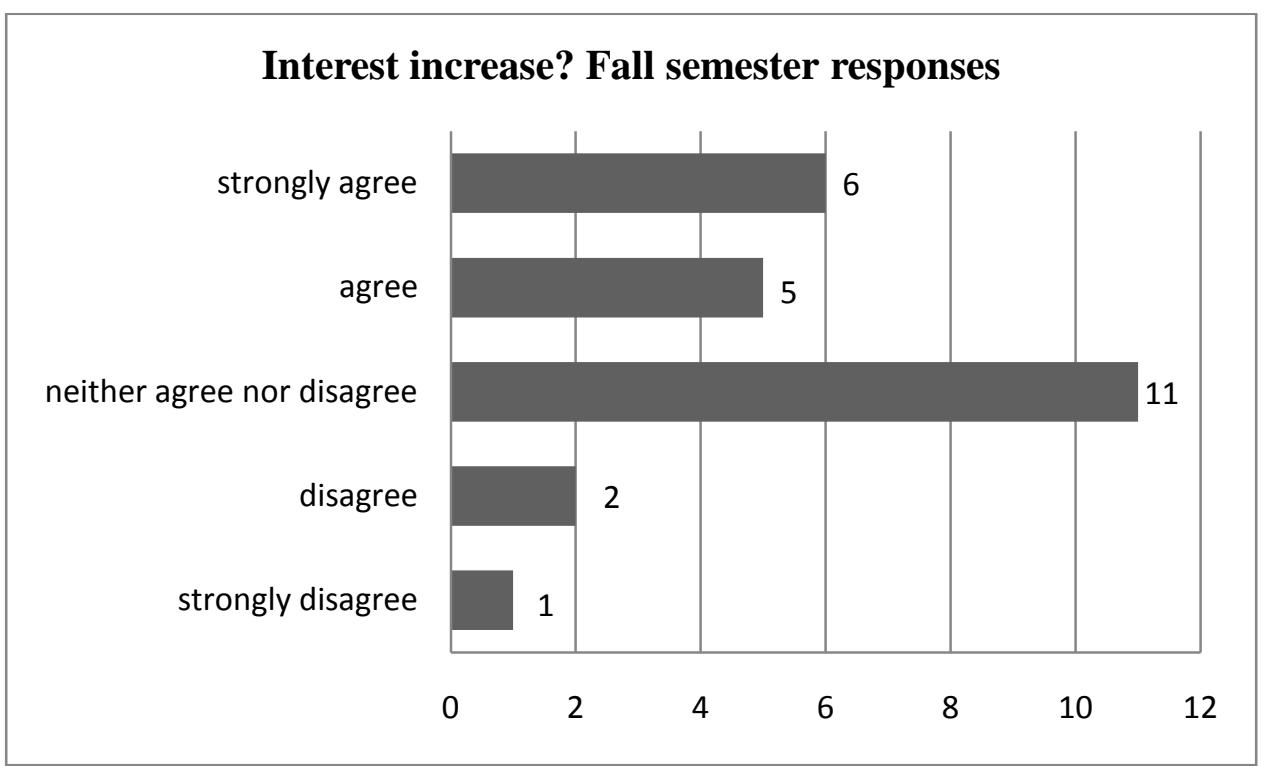

(Figure 9: Fall semester response: "Did the team-based project increase your interest in the topic?”)

What specifically did students from the winter and fall semesters say about how the project helped them to be more interested in the material? Below are representative comments.

Winter 2010 student comments on interest in the material:

- "Fluid dynamics was more interesting when I could see how it applied to everyday activities."

- "I had no interest in this topic until I took this class. This topic has helped me understand concepts in other classes as well." 
Fall 2010 student comments on interest in the material:

- "The team-based projects definitely helped me to see greater applications of Fluid Dynamics in the world."

Survey 2 Question: Did the project increase your applications of the topic?

The most successful aspect of the team-based projects was helping students to see applications of fluid dynamics principles all around them, thus helping them to conceptually integrate theory and practice. The overall mean response was 4.2 on the 5.0 Likert-type scale to the question (see Figure 10). The mean for the fall was a bit lower at 4.1 (see Figure 11) while for the winter was as high as 4.5 (see Figure 12). Clearly, students found team-based projects to be successful in helping them see applications of the fluid dynamics course content to the world around them.

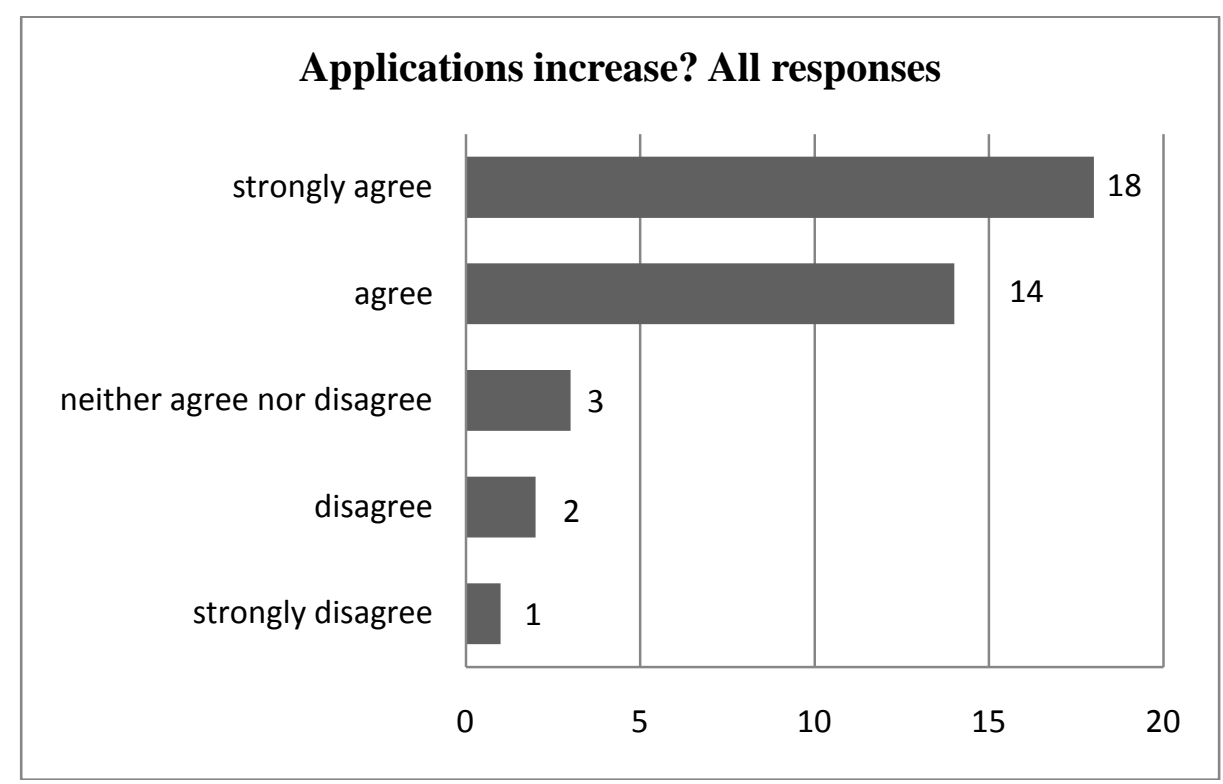

(Figure 10: Combined semester responses: "Did the team-based project increase the applications you see of the topic in the world around you?") 


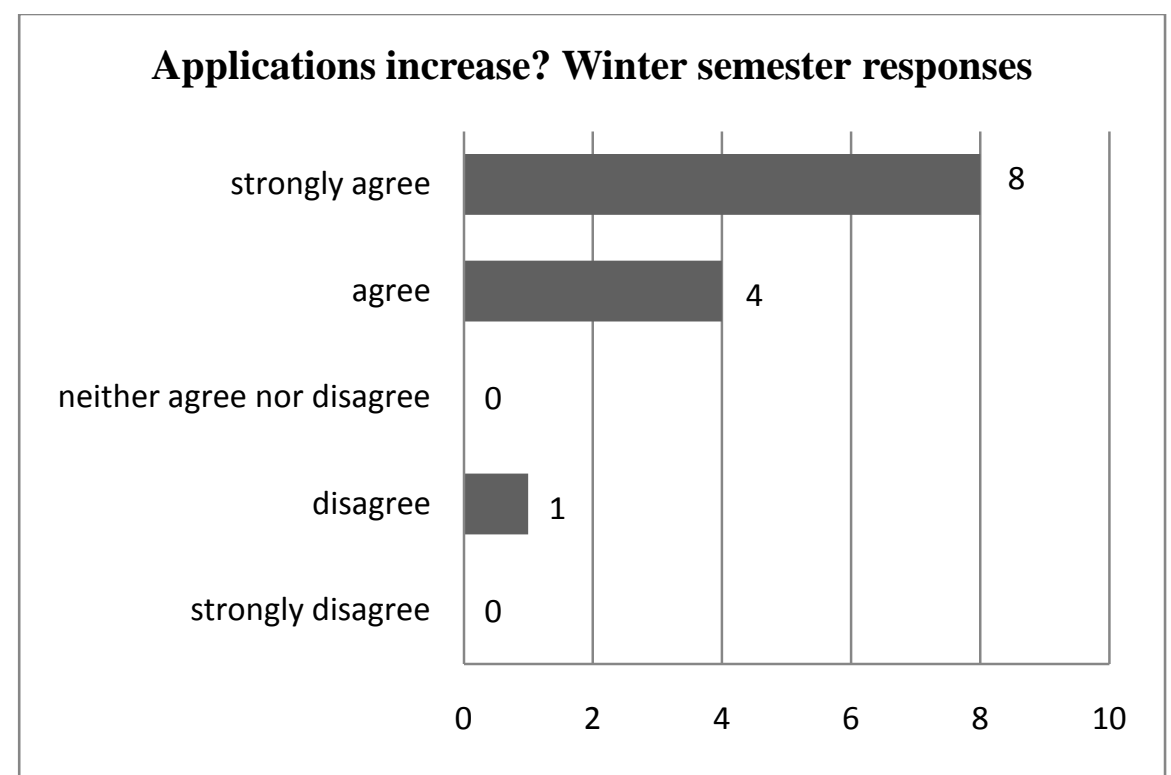

(Figure 11: Winter semester responses: "Did the team-based project increase the applications you see of the topic in the world around you?”)

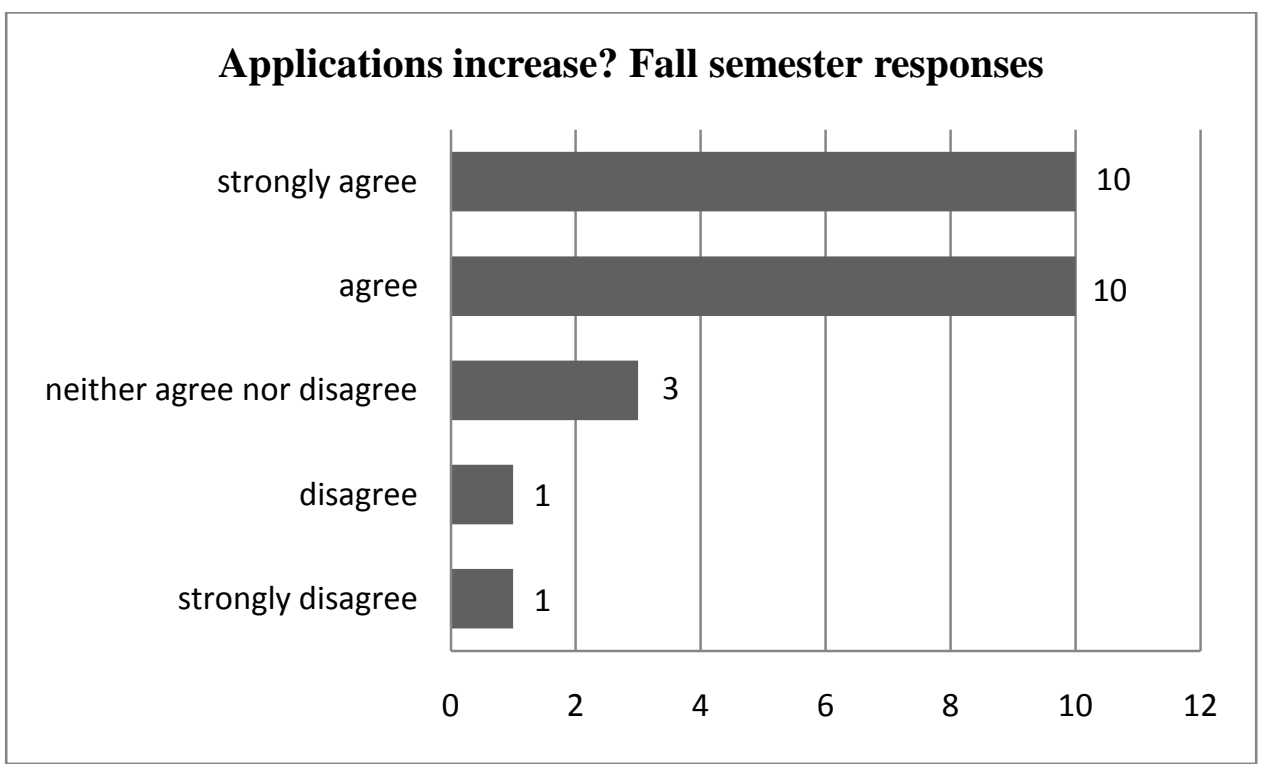

(Figure 12: Fall semester responses: "Did the team-based project increase the applications you see of the topic in the world around you?”)

What specifically did students from the winter and fall semesters say about how the project helped them to be see applications of the material in the world around them? A few comments will paint the picture.

Winter 2010 student comments on making connections with the course content to the world around them:

- "As I worked with my group to find a topic for the storyboard, I saw everyday examples of fluid dynamics." 
- "Trying to think of applications of the Reynolds Transport Theorem that the general public could relate to really helped me see many applications outside of engineering to the things that we studied."

Fall 2010 student comments on making connections with the course content to the world around them:

- "I was able to look a little deeper into one of the fundamentals of Fluid Dynamics and relate it to things that I see everyday around me. This helped me to see the application of this course in other areas of my life. Overall this project helped me become more involved and added interest in the subject."

- "I saw how the material applied to many facets of life and was all around me."

- "The team-based projects definitely helped me to see greater applications of Fluid Dynamics in the world."

- "By having to apply the Reynolds Transport Theorem to other things however, I have been able to see applications in other areas.”

Ambiguity or problems with teams or projects

Though the majority of the students had positive learning experiences in the class, some felt that the project was too ambiguous or didn't quite fit into the expectations of what an engineering class should be.

Winter 2010 student comments about assignment ambiguities:

- "I did not care for the project that was assigned in the fluid dynamics class. I did not think that it is practical to make an entertaining video centered around fluid dynamics, nor is it practical to try to make an educational fluid dynamics [class] entertaining, both cases require compromises that would make them less entertaining and less educational respectively."

- "It was hard for me to really understand the purpose of the project and thus have a strong desire to get involved in it."

Fall 2010 student comments about assignment ambiguities:

- "My group members hindered all of the [learning] outcomes. It made me hate the class."

- "I didn’t feel like I learned a tremendous amount about the Reynolds Transport Theorem by completing the storyboard. Maybe this was my own fault."

- "I felt like the storyboard project was not very effective in facilitating increased learning or understanding of any parts of fluid dynamics. It was not organized sufficiently. I spoke to several other students and we all felt like the project was something that should be in an art class and not an engineering class."

From a formative perspective, we have considered these comments us to help us improve the project-based assignment as we have prepared to implement it again in upcoming courses. We 
will work hard to explain the value of the project to student learning, clarify expectations, and provide multiple examples of successful projects.

\section{Conclusions}

This paper reported on student learning perceptions in a Civil Engineering course that introduced a team-based, project-based assignment to two different semesters of students. The purpose of this assignment was to help learners increase their interest in and understanding of the content matter-accomplished, in part, by learning to teach difficult concepts to others-enhance their capability to make connections with the course principles to the world around them, and to prepare them for industry experience by doing project-based and team-based work thus developing their teamwork and communication skills. Overall, the data reported in this case study generally align with what other researchers have found to be positive educational benefits for team-based project-based learning.

On the whole, the students' self-reports positively affirm that the team-based project activity increased their understanding of and interest in the topic and helped them to see Civil Engineering principle connections in the world around them. No students specifically recognized that this type of activity could help prepare them for real-world work experiences, especially in the engineering industry. However, such insights primarily emerge with perspective, after they have reached alumni status and are working in industry. ${ }^{18}$

From an instructional implementation viewpoint, the primary student concern with the projects, voiced on both surveys, is that students wanted more clarity regarding what was expected of them. We believe it is important to listen to student voices and to make appropriate changes. And certainly there are ways to make assignment expectations clearer. What is significant to notice about this trend in comments, however, is that students are acknowledging - though perhaps not being totally aware that this is what they experienced-that open-ended projectbased learning assignments are full of ambiguity as many other researchers have discussed. ${ }^{19,20,21,22,23}$ Engineering student are most comfortable with clear cut formulas that have specific uses and applications in specific contexts. They are not as comfortable with open-ended and ambiguous assignments, which may make them feel disoriented about how to achieve success or how to recognize success. Nevertheless, we believe it is important to expose learners to open-ended project-based learning earlier in their academic careers to better prepare them for real-world industry experience, or perhaps for engineering Capstone programs. Indeed, recent research makes this argument, that college engineering Capstone programs would be even more successful if students were exposed to project-based learning earlier in their schooling. ${ }^{18}$

Despite the ambiguity that often occurs in open-ended, project-based assignments, we learned from students and our reflections that instructors should do the following to minimize ambiguities:

- Provide a clear time-line of expected deliverables and due dates.

- Provide grading criteria up front.

- Make available numerous examples of each deliverable.

- And provide regular, substantive feedback throughout the process.

- If teamwork is used, consider reviewing literature on team formation best practices. 
- Use a small project, something that is well-defined, challenging, but achievable within the confines of an academic term. In fact, having a project that represents a minority portion of the grade in the class might help to keep the scope of the project in a manageable range.

We recognize that others educators who may wish to try this project-based learning approach may not have access to cash prizes or professional instructional media developers. They might also ask if the project-based assignment approach described in this paper is sustainable. We believe that with some small modifications this type of project-based assignment is sustainable and can be done with little or no expense. The "awards" of cash prizes and professional development appear to have had minimal impact on students' learning experiences. Indeed, as evidence, we simply point to the fact that few students actually won cash prizes and only one group each semester had the opportunity for their project to be professionally developed. If prizes were the crucial motivating factors for students to complete these projects, then we would not expect such high positive response rates from a majority of students each semester regarding the value they found in the project for their overall learning. Instead, we see that the project assignment itself was the primary factor in student motivation and learning, helping students tap into and develop latent interest in the topic material and thereby be positively engaged with it.

\section{References}

1. Mills, J. and D. Treagust, "Engineering education - is problem-based or project-based learning the answer?” Australasian Journal of Engineering Education, 2003, Vol. 11, pp. 2-16.

2. ABET, Criteria for Accrediting Engineering Programs: Effective for Evaluations During the 2010-2011 Accreditation Cycle, 2009, Baltimore, MD: Accreditation Board for Engineering Education, Inc. Retrieved: http://www.abet.org/Linked\%20Documents-UPDATE/Criteria\%20and\%20PP/E001\%201011\%20EAC\%20Criteria\%201-27-10.pdf.

3. ASCE BOK2, Civil Engineering Body of Knowledge for the $21^{\text {st }}$ Century: Preparing the Civil Engineer for the Future, $2^{\text {nd }}$ Edition, 2008, Reston, VA: American Society of Civil Engineers. Retrieved: http://www.asce.org/uploadedFiles/Leadership_Training__New/BOK2E_\%28ASCE_2008\%29_ebook.pdf.

4. Krajcik, J., and P. Blumenfeld, "Project-based learning” in The Cambridge Handbook of The Learning Sciences, R.K. Sawyer (ed.), 2006, Cambridge: Cambridge University Press, pp. 317-333.

5. Halverson, T. Distance Education Innovations and New Learning Environments: Combining Traditional Learning Methods and Emerging Technologies, 2009, Amherst, NY: Cambria Press. See especially chapter 3.

6. Stake, E. The Art of Case Study Research, 1995, Thousand Oaks, CA: Sage Publications.

7. $\quad$ PBLE, A Guide to Learning Engineering through Projects. Fund for the Development of Teaching and Learning, 2003, University of Nottingham. Retrieved: http://www.pble.ac.uk/pble-guide-final.pdf.

8. Gibson, I. "From solo-run to mainstream thinking: project-based learning in engineering design" European Journal of Engineering Education, 2003 Vol. 28, No. 3, pp. 331-337.

9. Anderson, L. and D. Krathwohl (eds). A Taxonomy for Learning, Teaching, and Assessing: A Revision of Bloom's Taxonomy of Educational Objectives, Abridged Edition, 2001, Boston: Allyn \& Bacon.

10. Savery, J. “Overview of problem-based learning: definitions and distinctions” The Interdisciplinary Journal of Problem-based Learning, 2006, Vol. 1. No. 1, pp. 9-20.

11. Dutson, A., R. Todd, S. Magleby, and C. Sorenson, “A review of literature on teaching engineering design through project-oriented capstone courses” Journal of Engineering Education, 1997, Vol. 86, No. 1, pp. 1728. 
12. Brickell, J., D. Proter, M. Reynolds, and R. Cosgrove, “Assigning students to groups for engineering design projects: A comparison of five methods” Journal of Engineering Education, 1994, Vol. 83 No. 3, pp. 259262.

13. Lumsdaine, M. and E. Lumsdaine, "Thinking preferences of engineering students: Implications for curriculum restructuring” Journal of Engineering Education, 1995, Vol. 84, No. 2, pp. 193-204.

14. Alfonseca, E., R. Carro, E. Martín, A. Ortigosa, and P. Paredes, "The impact of learning styles on student grouping for collaborative learning: A case study" User Modeling and User-Adapted Interaction, 2006, Vol. 16, Nos. 3-4, pp. 377-401.

15. Warnick, G., S. Magleby, R. Todd, and A. Parkinson, "Globalization: A new frontier for Capstone courses”, American Society of Engineering Education, 2008. Retrieved:

http://progdata.umflint.edu/MAZUMDER/Research/Engineering\%20education/globalization/globalization \%20using\%20capstone\%20courses.pdf.

16. Hox, J., and E. DeLeeuw, "A comparison of nonresponse in mail, telephone, and face-to-face surveys: Applying multilevel modeling to meta-analysis” Quality and Quantity, 1994, Vol. 28, No. 4, pp. 329-44.

17. Shih, T.-H., and X. Fan, "Comparing response rates from web and mail surveys: A meta-analysis" Field Methods, 2008, Vol. 20, No. 3, pp. 249-271.

18. Halverson, T., R. Todd, C. Mattson, and G. Warnick, "Industry experience and perspective: A survey of advice Brigham Young University Capstone alumni share with incoming students" accepted for presentation at ASEE Annual Conference, June 2011.

19. Felder, R., and M. Prince, PRISM, 2007, Vol. 17, No. 2, p. 55.

20. Prince, M., and R. Felder, "Inductive teaching and learning methods: Definitions, comparisons, and research bases” Journal of Engineering Education, 2006, Vol. 95, No. 2, pp. 123-138.

21. Lenschow, R., "From teaching to learning: A paradigm shift in engineering education and lifelong learning” European Journal of Engineering Education, 1998, Vol. 23, No. 2, pp. 155-161.

22. Gülbahar, Y. and H. Tinmaz, "Implementing project-based learning and e-portfolio assessment in an undergraduate course” Journal of Research on Technology in Education, 2006, Vol. 38, No. 3, pp. 309327.

23. Preuss, D., “Creating a project-based curriculum” Tech Directions, 2002, Vol. 62, No. 3, pp. 16-19. 